\title{
Antimicrobial Activities of Novel Bis-Piperidinium Compounds
}

\author{
MUHAMMAD JAWWAD SAIF, MOHAMMED ZUBER ${ }^{1}$, JAMIL ANWAR ${ }^{2}$ \\ and MUNAWAR ALI MUNAWAR ${ }^{2}$ \\ ${ }^{1}$ Department of Applied Chemistry, Government College University, Pakistan \\ ${ }^{2}$ Institute of Chemistry, University of the Punjab, Pakistan
}

Received 26 October 2011, revised 10 July 2012, accepted 10 July 2012

\begin{abstract}
The antimicrobial activity of two new series of bis-piperidinium compounds, with alkyl chains of different length, against bacterial (Escherichia coli, Pseudomonas aeruginosa, Staphylococcus aureus and Bacillus subtilis) and fungal strains (Aspergillus flavus, Aspergillus niger, Rhodolorula rubera, Lipomyces lopofera and Candida albicans), are described. Antimicrobial activities of the synthesized compounds were compared to that of dodecyltrimethylammonium chloride. Bis-piperidinium salts containing 12-16 carbon side chains showed better antimicrobial properties when compared to the standard dodecyltrimethylammonium chloride.
\end{abstract}

Ke y words: bis-piperidinium, quaternary ammonium, piperidinium, antimicrobial activity

The quaternary nitrogen group is an essential component for many biologically active compounds synthesized so far. Quaternary ammonium compounds (QACs) play an important role in living processes such as transmethylation reaction of lipid metabolism (cholin), nerve impulse transmission (acetylcholine) or metabolism of carbohydrates (from vitamins to carboxylases) (Burger and Wolff, 1995). QACs have relatively low toxicity and broad antimicrobial range, therefore are widely used in water sanitization, textile treatment, coating and food industry.

Antibacterial activity of long-chain quaternary ammonium compounds was reported for the first time by Domagk (1935). He pointed out that a large aliphatic chain attached to the quaternary nitrogen improved the antibacterial activity (Domagk, 1935). This work prompted many researchers and in relatively short time, the number of publications and patents on quaternary ammonium rapidly expanded. Bis-quaternary ammonium compounds contain two quaternary ammonium groups linked through a spacer group. Besides their phase-transfer catalytic properties, these compounds are now being studied for their biological applications (Kourai et al., 2006). Some studies on antimicrobial effects of bis-quaternary ammonium compounds have been already published. Mlynarčík et al. studied the influence of the length of alkyl chains in the derivatives of 1,3-propanediamine and its 2-hydroxy substituted analogue used as antibacterial agents on wool fibers (Mlynarčík et al., 1979). The results show clearly the efficacy of bis-quaternary ammonium compounds to protect the wool fabrics against the microorganisms (Infante et al., 1996). Similarly, another study focused on the applications of bis-quaternary ammonium compounds as wood preservatives (Zabielska-Matejuk et al., 2004) Antibacterial properties of bis-quaternary ammonium compound prepared from amines and epichlorohydrin (Chlebicki et al., 2005) hydroxypyridine were also reported (Kourai etal., 2006). Bis-quaternary ammonium compounds have also been used as phasetransfer catalysts in organic synthesis (Saif et al., 2010).

Given this very brief literature review, little data describing the antimicrobial properties of piperidinium compounds is available. To study antibacterial and antifungal properties of bis-piperidinium compounds, we synthesized two new series of compounds (2-13 and 15-26) and investigated their properties.

Twenty four bis-piperidinium compounds (2-13 and 15-26) were synthesized from readily available starting materials and tested for their antimicrobial properties. The synthesis of bis-piperidinium compounds are shown as Figures 1 and 2. 1,4-Bis(piperidin1-ylmethyl) benzene (1) was prepared as an intermediate product by substituting the bromine atoms at 1,4-bis(bromomethyl)benzene with piperidine in the presence of a base.

* Correspondending author: M.J. Saif, Department of Applied Chemistry, Government College University Faisalabad 38000, Pakistan; e-mail: jawwadsaif@gmail.com 


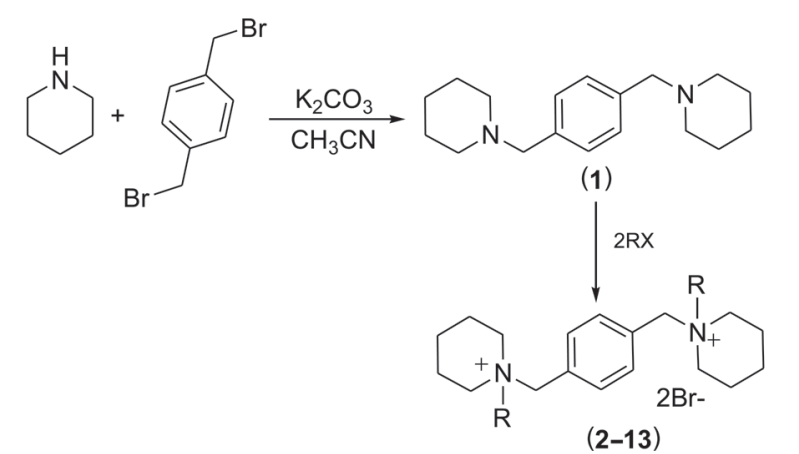

\begin{tabular}{|c|l|c|}
\hline Compound & \multicolumn{1}{|c|}{$\mathrm{R}$} & \% Yield \\
\hline 2 & $-\mathrm{CH}_{3}$ & 81 \\
\hline 3 & $-\mathrm{CH}_{2} \mathrm{CH}_{3}$ & 88 \\
\hline 4 & $-\mathrm{CH}_{2} \mathrm{CH}=\mathrm{CH}_{2}$ & 81 \\
\hline 5 & $-\left(n-\mathrm{CH}_{2}\right)_{3} \mathrm{CH}_{3}$ & 91 \\
\hline 6 & $-\left(n-\mathrm{CH}_{2}\right)_{5} \mathrm{CH}_{3}$ & 79 \\
\hline 7 & $-\left(n-\mathrm{CH}_{2}\right)_{7} \mathrm{CH}_{3}$ & 74 \\
\hline 8 & $-\left(n-\mathrm{CH}_{2}\right)_{11} \mathrm{CH}_{3}$ & 78 \\
\hline 9 & $-\left(n-\mathrm{CH}_{2}\right)_{15} \mathrm{CH}_{3}$ & 63 \\
\hline 10 & $-\left(n-\mathrm{CH}_{2}\right)_{17} \mathrm{CH}_{3}$ & 59 \\
\hline 11 & - benzyl & 84 \\
\hline 12 & 4 -bromobenzyl & 80 \\
\hline 13 & 3 -bromobenzyl & 81 \\
\hline
\end{tabular}

Fig. 1. Preparation of bis-piperidinium compounds (2-13)

Compounds (2-13) were prepared by quaternization of 1,4-bis(piperidin-1-ylmethyl)benzene (1) by using different alkyl halides. The most common procedure used for the quaternization of tertiary amines involves the addition of alkyl halide to the solution of tertiary amine in an appropriate solvent. 1,1'-(1,4-Phenyleneb is(methylene))bis(1-methylpiperidinium)diiodide (2) was prepared by quaternization of 1,4-bis(piperidin1-ylmethyl) benzene (1) in tetrahydrofuran (THF) with iodomethane. Rest of the compounds in the series were prepared using similar experimental protocols and suitable alkylating agents. 1,3-Substituted bis-piperidinium compounds were prepared from 1,3-bis(piperidin1-ylmethyl)benzene (14) according to scheme presented on Fig. 2.

Bis-piperidinium compounds (2-13 and 15-26) prepared during this work were screened for the antimicrobial activity against bacterial strains (Escherichia coli, Pseudomonas aeruginosa, Staphylococcus aureus and Bacillus subtilis) and fungal strains (Aspergillus flavus, Aspergillus niger, Rhodolorula rubera, Lipomyces lopofera and Candida albicans). The results are summarized in Tables I and II.

We focused on bacterial and fungal strains that are either pathogenic or cause opportunistic infections. The microorganisms were exposed to different concentrations of the investigated compounds. The antimicrobial

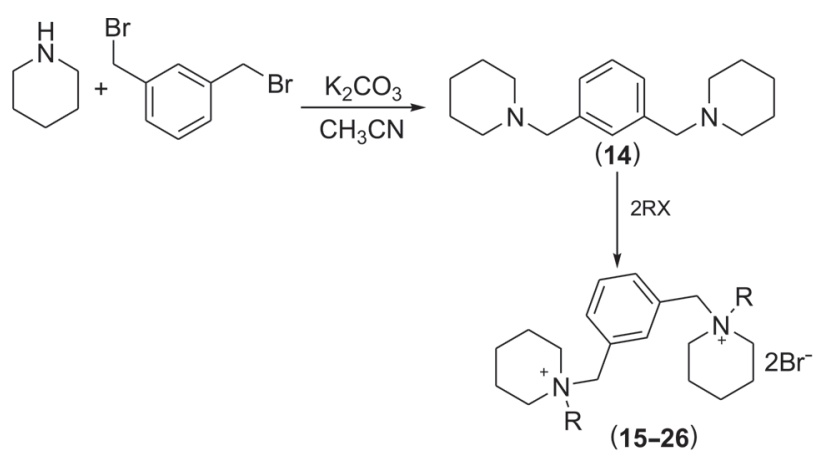

\begin{tabular}{|l|l|c|}
\hline Compound & \multicolumn{1}{|c|}{$\mathrm{R}$} & \% Yield \\
\hline 15 & $-\mathrm{CH}_{3}$ & 87 \\
\hline 16 & $-\mathrm{CH}_{2} \mathrm{CH}_{3}$ & 78 \\
\hline 17 & $-\mathrm{CH}_{2} \mathrm{CH}=\mathrm{CH}_{2}$ & 89 \\
\hline 18 & $-\left(n-\mathrm{CH}_{2}\right)_{3} \mathrm{CH}_{3}$ & 70 \\
\hline 19 & $-\left(n-\mathrm{CH}_{2}\right)_{5} \mathrm{CH}_{3}$ & 76 \\
\hline 20 & $-\left(n-\mathrm{CH}_{2}\right)_{7} \mathrm{CH}_{3}$ & 63 \\
\hline 21 & $-\left(n-\mathrm{CH}_{2}\right)_{11} \mathrm{CH}_{3}$ & 61 \\
\hline 22 & $-\left(n-\mathrm{CH}_{2}\right)_{15} \mathrm{CH}_{3}$ & 54 \\
\hline 23 & $-\left(n-\mathrm{CH}_{2}\right)_{17} \mathrm{CH}_{3}$ & 42 \\
\hline 24 & - benzyl & 83 \\
\hline 25 & 4 -bromobenzyl & 84 \\
\hline 26 & 3 -bromobenzyl & 78 \\
\hline
\end{tabular}

Fig. 2. Preparation of bis-piperidinium compounds (15-26)

activity of the tested compound was estimated as the lowest concentration that exhibits an inhibitory effect. Dodecyltrimethylammonium chloride (DTAC) was used as a reference compound. Test microbial strains exhibited the maximum sensitivity to compounds 8 and 21 that contain 12 carbons alkyl chain substitution of quaternary nitrogen. The activities of compounds 7, 9 10, 20, 22 and 23 with shorter hydrophobic alkyl chain were slightly lower. Compounds $2-6$ and 15-19 with short alkyl chain length ( $<8$ carbons) showed little activity. Compounds 11-13 and 24-26 with an aromatic ring also showed poor antibacterial activity. We can conclude that shortening of the side chain or replacement by aromatic ring resulted in loss of antimicrobial activity.

Previously Ahlstrom also reported that quaternary ammonium compounds with a $\mathrm{C}_{16}$ lypophilic alkyl chain demonstrated higher antibacterial activity when compared to compounds containing shorter alkyl chains (Ahlstrom, 1999). This observation possibly can be attributed to long chain interacting with the fatty acid portion of lipid A and quaternary ammonium compounds are able to cause cell leakage and membrane damage upon their adsorption to the bacterial membrane (Hamilton, 1968). In our work, we observed variable activity of piperidinium compounds against different microorganisms. The differences in cell wall composition of Gram-negative (P.aeruginosa) and 
Table I

Antibacterial activity of bis-piperidinium compounds (2-13 and 15-26)

\begin{tabular}{|c|c|c|c|c|}
\hline \multirow{2}{*}{$\begin{array}{c}\text { Compound } \\
\text { No. }\end{array}$} & \multicolumn{4}{|c|}{$\begin{array}{l}\text { Minimum lethal concentration of the compound } \\
\qquad[\mu \mathrm{g} / \mathrm{ml}]\end{array}$} \\
\hline & E. coli & P. aeruginosa & A. niger & B. Subtilis \\
\hline 2 & 5000 & $>5000$ & 5000 & $>5000$ \\
\hline 3 & 5000 & $>5000$ & 5000 & $>5000$ \\
\hline 4 & 5000 & $>5000$ & 5000 & $>5000$ \\
\hline 5 & 2500 & 5000 & 2500 & $>5000$ \\
\hline 6 & 1250 & 5000 & 5000 & 2500 \\
\hline 7 & 625 & 625 & 1250 & 1250 \\
\hline 8 & 150 & 150 & 300 & 150 \\
\hline 9 & 150 & 300 & 625 & 300 \\
\hline 10 & 625 & 625 & 1250 & 625 \\
\hline 11 & 5000 & 5000 & 5000 & 5000 \\
\hline 12 & 5000 & 5000 & 5000 & 5000 \\
\hline 13 & 5000 & 5000 & 5000 & 5000 \\
\hline 15 & 5000 & $>5000$ & $>5000$ & $>5000$ \\
\hline 16 & 5000 & $>5000$ & $>5000$ & $>5000$ \\
\hline 17 & 5000 & 5000 & $>5000$ & $>5000$ \\
\hline 18 & 2500 & 5000 & $>5000$ & 5000 \\
\hline 19 & 1250 & 5000 & 5000 & 2500 \\
\hline 20 & 625 & 625 & 1250 & 1250 \\
\hline 21 & 150 & 150 & 300 & 150 \\
\hline 22 & 150 & 300 & 625 & 300 \\
\hline 23 & 625 & 625 & 1250 & 625 \\
\hline 24 & 5000 & 5000 & 5000 & $>5000$ \\
\hline 25 & 5000 & 5000 & 5000 & 5000 \\
\hline 26 & 2500 & 5000 & 2500 & 5000 \\
\hline DTAC $^{*}$ & 300 & 2500 & 1250 & 1250 \\
\hline
\end{tabular}

* DTAC $=$ Dodecyltrimethylammonium chloride

Gram-positive bacteria (S. aureus) may be a cause of different resistance levels to the tested compounds. For example, the relatively low permeability of the outer membrane of Gram-negative bacteria may play a key role in the defense of bacteria as the penetration of antibacterial substances is slowed down.

\section{Acknowledgment}

We are grateful to Higher Education Commission, Pakistan for providing the financial support to carry out this research work.

\section{References}

Ahlstrom B., R.A. Thompson and L. Edebo. 1999. The effect of hydrocarbon chain length, $\mathrm{pH}$ and temperature on the binding and bactericidal effect of amphiphilic betaine esters on Salmonella typhinurium. APMIS, 107: 318-324

Burger A. and M.E. Wolff. 1995. Burger's Medicinal Chemistry and Drug. Discovery, 5, Wiley

Chlebicki J., J. Wegrzynska, I. Maliszewska and M. Oswiecimska. 2005. Preparation, surface-active properties, and antimicro-
Table II

Antifungal activity of bis-piperidinium compounds (2-13 and 15-26)

\begin{tabular}{|c|c|c|c|c|c|}
\hline \multirow{2}{*}{$\begin{array}{l}\text { Compound } \\
\text { No. }\end{array}$} & \multicolumn{5}{|c|}{$\begin{array}{l}\text { Minimum lethal concentration of the compound } \\
\qquad[\mu \mathrm{g} / \mathrm{ml}]\end{array}$} \\
\hline & A. flavu & R. rubera & S. aureus & L. lopofera & C. albicans \\
\hline 2 & $>5000$ & $>5000$ & 5000 & $>5000$ & $>5000$ \\
\hline 3 & $>5000$ & $>5000$ & 5000 & $>5000$ & $>5000$ \\
\hline 4 & 5000 & $>5000$ & 5000 & $>5000$ & $>5000$ \\
\hline 5 & $>5000$ & 5000 & 2500 & $>5000$ & $>5000$ \\
\hline 6 & 5000 & 2500 & 1250 & 2500 & 5000 \\
\hline 7 & 1250 & 1250 & 625 & 1250 & 1250 \\
\hline 8 & 300 & 150 & 150 & 150 & 300 \\
\hline 9 & 300 & 300 & 150 & 300 & 625 \\
\hline 10 & 625 & 625 & 625 & 625 & 625 \\
\hline 11 & 5000 & 5000 & 2500 & 5000 & 5000 \\
\hline 12 & 5000 & 5000 & 2500 & 5000 & 5000 \\
\hline 13 & 5000 & 5000 & 2500 & 5000 & 5000 \\
\hline 15 & $>5000$ & $>5000$ & 5000 & $>5000$ & $>5000$ \\
\hline 16 & $>5000$ & $>5000$ & 5000 & $>5000$ & $>5000$ \\
\hline 17 & 5000 & 5000 & 5000 & 5000 & 5000 \\
\hline 18 & 5000 & 5000 & 2500 & 5000 & 5000 \\
\hline 19 & 2500 & 2500 & 1250 & 2500 & 2500 \\
\hline 20 & 1250 & 1250 & 625 & 1250 & 1250 \\
\hline 21 & 300 & 150 & 150 & 300 & 300 \\
\hline 22 & 300 & 300 & 150 & 300 & 300 \\
\hline 23 & 625 & 625 & 300 & 625 & 625 \\
\hline 24 & 5000 & 5000 & 2500 & 5000 & 5000 \\
\hline 25 & $>5000$ & 5000 & 5000 & 5000 & $>5000$ \\
\hline 26 & 5000 & 5000 & 2500 & 5000 & 5000 \\
\hline DTAC $^{*}$ & 625 & 300 & 300 & 625 & 625 \\
\hline
\end{tabular}

* DTAC $=$ Dodecyltrimethylammonium chloride

bial activities of bis-quaternary ammonium salts from amines and epichlorohydrin. Journal of Surfactants and Detergents, 8: 227-232 Domagk G. 1935. A new class of disinfectants. Dtsch. Med. Wochenschr. 61: 829-832

Hamilton W.A. 1968. The mechanism of the bacteriostatic action of tetrachlorosalicylanilide: a membrane-active antibacterial compound. J. Gen. Microbiol 50: 441-458

Infante M.R., M. Diz, A. Manresa, A. Pinazo and P. Erra. 1996. Microbial resistance of wool fabric treated with bis-Quats compounds. Journal of Applied Microbiology, 81: 212-216

Kourai H., T. Yabuhara, A. Shirai, T. Maeda and H. Nagamune. 2006. Syntheses and antimicrobial activities of a series of new bisquaternary ammonium compounds. European Journal of Medicinal Chemistry, 41: 437-444

Mlynarčík D., I. Lacko and F. Devínsky. 1979. Antimicrobial effect of bis-quaternary ammonium salts derived from 1,3-propanediamine. Cellular and Molecular Life Sciences (CMLS), 35: 1044-1045 Saif M.J., J. Anwar and M.A. Munawar. 2010. Novel bis-piperidinium compounds as versatile phase-transfer catalysts. Arkivoc 133-145

Zabielska-Matejuk J., E. Urbanik and J. Pernak. 2004. New bisquaternary ammonium and bis-imidazolium chloride wood preservatives. Holzforschung, 58: 292-299 